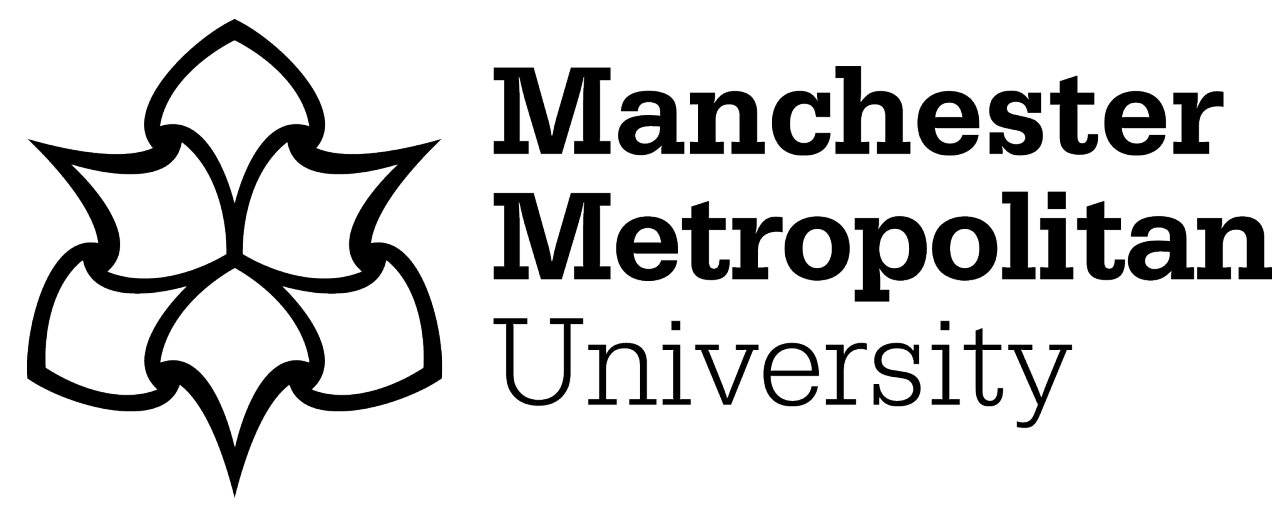

Ruvalcaba-Paredes, EK, Hidalgo-Bastida, LA, Sesman-Bernal, AL, Garciadiego-Cazares, D, Pérez-Dosal, MR, Martínez-López, V, VargasSandoval, B, Pichardo-Bahena, R, Ibarra, C and Velasquillo, C (2016) Osteogenic potential of murine periosteum for critical-size cranial defects. British Journal of Oral and Maxillofacial Surgery, 54 (7). pp. 772-777. ISSN 0007-117X

Downloaded from: https://e-space.mmu.ac.uk/614873/

Version: Accepted Version

Publisher: Elsevier

DOI: https://doi.org/10.1016/j.bjoms.2016.05.001

Usage rights: Creative Commons: Attribution-Noncommercial-No Derivative Works 4.0

Please cite the published version 
Ruvalcaba E, Hidalgo-Bastida LA, et al.

\title{
Osteogenic Potential of Murine Periosteum for Critical-Size Cranial Defects
}

\begin{abstract}
Bone tissue engineering has combined bespoke scaffolds and osteo-inductive factors to maintain functional osteoprogenitors cells. Periosteal osteoblasts have been confirmed as a suitable osteoblast source for bone tissue engineering. Suitable matrices have been identified to support cell proliferation and differentiation: Demineralised Bone Matrix (DBM), a compatible and osteoinductive matrix, and Acellular Human Dermis (AHD), which supports fibroblasts proliferation. This study evaluated the osteogenic potential of an Osteogenic Unit (OU), developed by combining periosteum, DBM and AHD, in a rodent model of critical size cranial defect. Briefly, remnants from the superior maxillary periosteum were used to harvest cells, which were characterised by flow cytometry and RT-PCR. Cells were cultures into the OU and assessed for viability before implanting these constructs in rodent models. These were compared to the control group after three months. Histological analysis by Hematoxylin-Eosin (H\&E), Von Kossa and immunostainings, confirmed viable cells positive for CD90, CD73, CD166, Runx-2, OPN and Col-I in the OU group, while the control group presented connective tissue joined bone edges of injury zone. We can conclude that OU constructs have osteogenic and regenerative potential to be used in bone tissue engineering.
\end{abstract}

Keywords: Neotissue, Regeneration, Tissue Engineering, Periosteum, Osteogenic Unit (OU). 


\section{Introduction}

The accidents and traumas impact on populations' health is significant in many countries. Worldwide annually approximately 1.2 million people die by accidents. In Mexico, this is the third cause for mortality in adults and the first in children. One of the main traumas with permanent disability risk is the cranial trauma, which needs long-term hospitalisation for treatment and still results on long-lasting complications. ${ }^{1-4}$

Traditionally, bone lesions caused by cranial trauma are treated with autologous bone grafts, which are used by surgeons to restore the shape and function on the skull. However, long-term follow up of these patients shows that such cranial reconstructions are compromised by graft reabsorption. In addition to the soft tissue prolapse, the rapid migration of fibroblasts into the bone defect has been identified as an obstacle for osteo-regeneration. This has been overcome by using a "guided bone regeneration" technique, which uses membranes designed to act as a barrier to stop the prolapse of the adjacent soft tissue, as well as fibroblast infiltration. ${ }^{5}$ Cranial reconstruction continues to be a challenge not fully addressed by current conventional treatments, as these cannot restore loss bone tissue. Bone tissue engineering offers an alternative to regenerate cranial defects by using an extracellular matrix (either synthetic or natural), bioactive molecules (growth and differentiation factors), and cells to regenerate the damaged tissue. $^{6}$

Not all human cells present good proliferation and differentiation potential in vivo and/or in vitro. One of the suitable cells for bone tissue engineering are mesenchymal stem cells (MSC), which can be found on adult tissues such as bone marrow, adipose tissue, blood, and periosteum, and can retain the ability to differentiate into specific lineages. ${ }^{7}$ The periosteum is a connective tissue membrane, micro-vascularised, that covers the external surface of bone. This is formed by two layers, the external with fibroblasts and Sharpey fibres, and the internal, with mesenchymal stem cells and osteoprogenitors to support normal bone growth, repair and regeneration. Hence, periosteal mixed populations include fibroblasts, osteoblasts, MSCs and pericytes. The periosteum plays an essential role in bone development and repair. Applications could also be therapeutic in craniofacial bone regeneration. ${ }^{7-9}$

Previous works show that periosteal cells can differentiate into bone and cartilage. ${ }^{10}$ Periosteal tissue grafting has demonstrated successful results in bone regeneration. The regeneration of an engineered, functional periosteum-like tissue could aid in bone regenerative therapies. ${ }^{11} \mathrm{An}$ 
advantage of harvesting periosteum for clinical applications, including cleft palate surgery, is that this can be obtained from the oral cavity with minimum morbidity at the donor site. ${ }^{12}$

Tissue engineering requires scaffolds that mimic the biological cues for induction and development of Neotissue. ${ }^{6}$ Several research groups have demonstrated potential bone substitutes suitable for clinical use. This ideal substitute needs to be cheap, readily available, easy to handle, radiotransparent, biocompatible, osteo-inductor (able to induce differentiation of stem cells into osteoblasts) and osteo-conductive (bone growth from existing bone tissue). ${ }^{13}$

Non-re-absorbable materials used previously for cranial reconstruction, such as acrylics, metals and ceramics, have been associated with complications including skin rupture, graft exposure, extrusion and infection. ${ }^{14}$ Paediatric patients have the additional disadvantage that such grafts need to be replaced to match their ongoing growth rate.

An alternative to these materials is a Demineralised Bone Matrix (DBM), which is biocompatible and osteoinductive. Several studies have reported that after DBM implantation on cranial defects, local MSCs proliferate and differentiate into cartilage and then into neobone. ${ }^{15,16}$

Furthermore, results with Acellular Human Dermis (AHD) for cranial reconstruction demonstrated to support homing of fibroblasts and their proliferation, as well as rapid neovascularisation. This AHD, from cadaveric human skin, is formed by collagen type IV and type VII, elastin and laminin..$^{15,17}$

This team has worked previously developing biological substitutes for tissue regeneration and repair, focusing on critical size-cranial defects, confirming the potential of an Osteogenic Unit (OU) formed by AHD, DBM and bone-marrow MSCs. This graft retains osteoconductive, osteoinductive and osteogenic properties for neobone. The periosteum is a suitable source of MSCs with osteogenic potential and minimal morbidity when harvesting them. The objective of this study is to assess new bone tissue formation when combining the OU and periosteal cells in a preclinical model of athymic mice with bone cranial defects. 


\section{Materials and Methods}

\section{Cellular Isolation and Culture}

Biopsies were taken from surgery remnants from cleft palate procedures in paediatric patients. The periosteum remnant was from the anterior region of the superior maxilla. The group included samples from seven paediatric patients, whose parents granted permission for its use for research. Periosteal biopsies of $0.3 \times 0.3 \mathrm{~cm}$ (approximately) were incubated in DMEM/F12 (Gibco ${ }^{\circledR}$, USA) with penicillin-streptomycin and amphotericin B (Gibco ${ }^{\circledR}$, USA), and transported at $2^{\circ}$ a $4^{\circ} \mathrm{C}$ from the surgical theatre to the research unit at the National Institute of Rehabilitation. Biopsies were then cut into two similar squares of $0.15 \mathrm{~cm} \times 0.15 \mathrm{~cm}$ and then placed in Petri dishes (BD Falcon, USA). Cells were cultures in DMEM-F12 with 10\% of Fetal Bovine Serum (FBS, Gibco®, USA), supplemented with penicillin-streptomycin and amphotericin B (Gibco®, USA), and incubated at $37^{\circ} \mathrm{C}, 5 \%$ of $\mathrm{CO}_{2}$. Media was replenished two/three times a week until confluence.

\section{Cellular Viability}

Prior to the OU implant into the in vivo models, cell viability was verified by seeding $5 \times 10^{4}$ cells and incubating with LIVE/DEAD kit (Invitrogen, Carlsbad, CA, USA) before visualising by inverted fluorescent microscope (Carl Zeiss Micro-Imaging, Thornwood, NY).

\section{Immunophenotypic characterisation}

Flow cytometry (FACSCalibur $\left.{ }^{\circledR}\right)$ was used to characterise samples of 250000 cells labelled with monoclonal antibodies for hematopoietic cell markers [anti-CD14-APC (BD Pharmigen TM), anti-CD34-APC (BD Pharmigen TM), anti-CD45-FITC (BD Pharmigen TM)] and MSCs markers [anti-CD73-PE (BD Pharmigen TM), anti-CD90-FITC (BD25 Pharmigen TM), antiCD166 (Santa Cruz Biotechnology, Inc.)]. Results were used to determine the percentage of MSC in the periosteum using Cell Quest PRO TM (Becton Dickinson).

\section{RNA Extraction and RT(Reverse Retrotranscriptase-)-PCR}

In order to confirm the osteogenic potential of periosteum cells, RNA was extracted from confluent cells prior to implant. Briefly, RNA was extracted using TRIZOL ${ }^{\circledR}$ (Invitrogen, CA, USA), following the supplier's protocol. Total RNA was dissolved in $30 \mu \mathrm{L}$ of DEPC (Diethylpyrocarbonate, Sigma-Aldrich) water and stored at $-80^{\circ} \mathrm{C}$ until analysis. RNA 
concentration was determined using a spectrophotometer GeneQuant pro (Amersham

Biosciences) ${ }^{\circledR}$. Reverse transcription was used to obtain cDNA from $1 \mu \mathrm{g}$ of total RNA total by using the 1st Strand cDNA Synthesis Kit for RT-PCR (AMV)® (Roche Applied Science). The PCR was conducted in a thermocycler (Eppendorf Ag, Master cycler gradient), with a final volume of $20 \mu \mathrm{l}$ of reaction. Osteogenic markers included Runx-2, Osteopontin (OPN) y Collagen type I (Col-I) and were normalised to the housekeeping gene GAPDH (glyceraldehydo-3-Fosfatase-deshidrogenase). Full temperature sets and primer sequences are shown in table 1. Gels were visualised in an Aplhamager Gel Documentation (Alpha Innotech () .

\section{$\underline{\text { In vivo Model }}$}

All animals were treated in accordance with Public Health Service Policy on Humane Care and Use of Laboratory Animals (August 2002), implemented by the Office of Laboratory Animal Welfare, Harvard Medical School IACUC. Cells were harvested at $80 \%$ confluence and seeded at $5 \times 104$ cells into BDM and later onto AHD, forming the $\mathrm{OU}$ for the in vivo model. Five weeks old athymic mice nu/nu, with a $5 \mathrm{~mm} 2$ (critical size) cranial defects, was used to evaluate the implant of the $\mathrm{OU}$; this procedure was carried out in the bioterium operating room under sterility conditions, in the immunocompromised animals unit at the National Rehabilitation Institute. After three months, mice were euthanized for a craniotomy to remove the regenerated area, which was fixed in 4\% PFA (Paraformaldehyde) until analysis.

\section{Histological and Immunohistochemistry Analysis}

Fixed craniotomy samples were dehydrated and transferred to xylene for paraffin embedding. These samples were sectioned at $5 \mu \mathrm{m}$. Slides were stained in Hematoxylin and Eosin (H\&E). Immunohistochemistry analysis was done for Col-I (1:50; anti-goat polyclonal antibody, Santa Cruz, Santa Cruz, CA), Runx-2 (1:50; anti-goat polyclonal antibody, Santa Cruz, Santa Cruz, CA), Alkaline Phosphatase (1:50; anti-rabbit polyclonal antibody, Santa Cruz, Santa Cruz, CA) and Osteopontin (1:50; anti-goat polyclonal antibody, Santa Cruz, Santa Cruz, CA). Secondary antibodies from ABC Elite VECTASTAIN kit (Vector Laboratories) were diluted 1:100 and visualised with Liquid DAB+ kit (Dako Cytomation) and Hematoxylin. Samples were gelatinecoated and analysed under the microscope (Axio-observer, Karl-Zeiss). For bone formation, Von Kossa staining was used by incubating the samples with $1 \%$ silver nitrate and UV light for 1 hour. These were washed and incubated with 5\% sodium thiosulphate for 5 minutes before staining with rapid red. 


\section{Results}

Periosteal Cells from the biopsied superior maxilla remained viable and expressed osteomarkers in vitro

Cell viability was assessed by fluorescent microscopy using calcein, according to the supplier's information. This showed viable cells onto the OU, as can be seen in Figure 1 .

The gene expression analysis of the periosteal cells was confirmed by Runx-2, OPN and Col-I, in addition to $G A D P H$, the housekeeping gene. After four weeks of cell culture, Runx-2, $O P N$ and Col-I remained expressed in all samples cultured in vitro. This confirms periosteal cells preserved their osteogenic potential (Fig 1B) prior to implantation.

\section{Periosteal Cells from the biopsied superior maxilla expressed markers for MSCs}

In order to assess the percentage of the MSCs population from the periosteum biopsy and their differentiation potential, cell phenotype was analysed using flow cytometry. Results show that $92.87 \%$ were positive for CD90 (fig. 1C), $48.91 \%$ for CD73 (fig. 1D), and $2.38 \%$ for CD166 (fig. 1E). Hematopoietic markers were also analysed, CD34 (fig. 1F), CD45 (fig. 1G), and CD14 (Fig. $1 \mathrm{H}$ ), expressed in $2.15 \%, 0.82 \%$ y $0.27 \%$, respectively, as can be seen in Figure 1 .

\section{Periosteal Cells from the biopsied superior maxilla seeded onto the Osteogenic Unit preserved their phenotype.}

The osteogenic potential of the OU in the animal models were analysed by H\&E, which confirmed that the OU supported formation of neo-tissue in vivo, this was structurally similar to bone (Fig 2a). Bone trabeculae and hematopoietic cells were present at the periphery, with osteoblasts at the centre forming immature bone, and osteoprogenitor cells in between the periphery and centre. The control group with no OU implant only showed connective tissue joining the boundaries of the cranial defect but no neo-tissue (Fig 2a).

Immunohistochemical analysis of the explanted neo-tissue was performed to evaluate the formation of de novo bone in the neo-tissue. This was positive for $O P N$ (fig. 2b), Col-I (fig. 2c), Runx-2 (fi. 2d) and FA (fig. 2e), all of them characteristic proteins of bone metabolism. Mineralisation was confirmed by Von Kossa, which shows dark calcium deposits as can be seen in Fig $2 \mathrm{f}$. 


\section{Discussion}

Periosteal tissue grafting has demonstrated successful results in bone regeneration; the presence of a functional periosteum accelerates healing in bone defects by providing a source of progenitor cells that aid in repair. ${ }^{11}$ In 1742, Duhamel studied the osteogenic potential of periosteum. Ollier showed the role played by the periosteum in bone regeneration, ${ }^{18}$ while Fell was the first to successfully culture periosteum and concluded that this tissue might have the capability to form mineralized tissue in vitro. ${ }^{19}$ Several teams have confirmed periosteal cells' ability to promote bone tissue formation and the relatively easy harvesting from the oral cavity, minimising morbidity. ${ }^{20,12}$ This study proves that periosteal cells from cleft palate surgery can be harvested and expanded in vitro. We propose that non-invasive surgery could be performed to obtain periosteal cells as an autologous treatment for patients with bone defects, such as cleft palate or cranial defects. This could be particularly useful in paediatric cases where standard implants need to be replaced as the patient continues to grow. The method we use to perform this study could be successful, because the first place the AHD serves as a barrier and allows us to preserve the integrity of the mass of the brain without compromising the risk of infiltration, it is for this reason that has not been used cells directly over the lesion so that they were not in direct contact with the brain mass. We propose that the AHD served us as a barrier and material support (scaffold) for the combination of demineralized bone cells, ensuring that bone formation does not invade the brain mass and not cause any damage.

The study confirmed that periosteal cells preserved their osteogenic potential not only in in vitro monolayer culture but more importantly, when culture into the OU and implanted into animal models, promoting de novo bone formation.

As described previously, the periosteal cells are a mixed population that include fibroblasts, MSCs and periocytes. The MSCs cells have been confirmed by the presence of surface markers for CD9, CD90, CD73, CD105, CD166, but negative for CD34 and CD45. ${ }^{7}$ Pittenger and Dominici defined CD29, CD73, CD90 and CD105 are indicative of MSC phenotype. MSC do not express the haematopoietic marker CD45 and express the adhesion molecules CD166 and CD140b. ${ }^{21,22}$ Some research suggests that the MSCA-1 (Mesenchymal stem cell antigen-1) and CD166 positive have high osteogenic potential compared with MSCA1 and CD166 negative. ${ }^{23}$ Periosteal cells from cleft palate surgery expressed positive markers for CD90, CD73, and a reduced CD166; however, expression CD34, CD45, and CD14, were considered negative as results were $2.15 \%, 0.82 \%$ and $0.27 \%$, respectively. This confirms a limited presence of MSCs in the biopsies. This could be because biopsy cells are of type osteogenic, or it could also be that in this fragment size was very small; in the future propose we 
to do a study in which evaluate the percentage of MSC in different sizes fragments and compare the osteogenic potential of cells CD166 positive.

Results from RT-PCR suggest that our population is mainly osteoblasts, as we had high levels of expression of Runx-2 (essential nuclear proteins for bone morphogenesis), Col-I and $O P N$, all synthesised by osteoblasts. It is possible that the osteogenic phenotype had been retained from the in vivo osteo-differentiation signalling prior to the cell harvest, which is also supporting the periosteal MSC population into osteo-differentiation.

Biomaterial properties are keys in tissue engineering both as physical supports for 3D cell seeding and proliferation, as well as for bioactive molecules delivery. ${ }^{5}$ The materials used for the OU has not cytoxic effect on periosteal cells, confirmed by viability assays and imaging. Hence, this combination of DBM and AHD supports cell adhesion and proliferation, in addition to maintain differentiated phenotypes such as the periosteal osteoblasts. This could also promote osteodifferentiation in periosteal MSCs.

Staining with H\&E confirmed that de novo bone with similar characteristics to those in bone tissue, including trabecular structure, in the in vivo model. However, the control group only showed connective tissue joining the edges of the bone defect. Further immunostainings with Runx-2, essential for osteoblastic differentiation and bone morphogenesis; $O P N$, indicating high affinity to hydroxyapatite binding; Col-I and AlkPhos, an early marker for osteogenic differentiation, were all positive for the OU group. Bone Morphonogenic proteins (BMPs) promote Runx-2 transcription, which is directly involved in AlkPhos, OPN and Col-1 gene expression. ${ }^{24}$ Hence, it is possible that the BMPs from the DBM's could have also contributed to retain the osteogenic potential of periosteal cells and its MSCs osteo-differentiation. These results indicate that the OU contains viable osteoblasts that can produce collagen matrix and synthesis of AlkPhos and $O P N$ when implanted in this animal model. Moreover, bone mineralisation confirms successful differentiation in neotissues. The Von Kossa staining corroborates the presence of calcium deposits and mineralisation in the OU group.

Osteoblasts express a high osteogenic potential and bone matrix production, thus, they are often used for cell seeding for regenerative therapies. ${ }^{25}$ Periosteal osteoblasts could offer a suitable source with low morbidity if cells are harvested from alveolar bone. This alveolar bone, which lines the alveoli in the maxilla, is easy to access from the oral cavity, therefore less invasive than bone marrow harvesting. 


\section{Conclusion}

The study confirms that remaining tissue from cleft palate or lip correction surgery can be cultured and expanded in vitro before combining them with biomaterials such as DBMAHD, and still preserve its bone regenerative potential. This OU, formed by periosteal cells, $\mathrm{DBM}$ and $\mathrm{ADH}$, not only preserved its cellular function, but also promoted bone regeneration and mineralisation, collagen matrix formation and AlkPhos synthesis, in defects of critical size. Hence, further work is needed in order to quantify osteoblasts/MSCs populations, and to establish the efficiency of the MSCs' osteo-differentiation, before this can be used as a clinical therapy for de novo bone graft for critical size maxillofacial defects or cleft palate.

\section{Acknowledgments}

The authors thank Xochitl Guerrero Alva and Carlos Landa Solis for their support in this study. This work was funded by CONACyT - Sectorial Project 114359. 


\section{References}

1. Osornio-Ruiz JL, Martínez-Ibarra SI, Torres-González R, Reyes-Hernández RI. Lesiones traumáticas en niños que requieren hospitalización. Rev Med Inst Mex Seguro Soc 2007;45 (2): $133-140$.

2. Cano-Rodríguez AI, Martínez-Pecina RE, Caballero-Talavera T, Cano-Muñoz I, SánchezLópez I. Análisis de signos clínicos y hallazgos radiográficos en pacientes pediátricos con diagnóstico de traumatismo craneoencefálico. An Rad Mex 2009; 3:211-220.

3. Bejarano ML, Ramírez D, Ramírez MM. Traumatismo craneoencefálico en niños: relación entre los hallazgos tomográficos y el pronóstico. Rev Esp Med Quir 2008;13(2):60-68.

4. Programa Nacional de Salud 2001-2006: Prevención y Rehabilitación de Discapacidades PreveR-Dis. La Democratización de la Salud en México, Hacia un sistema universal de Salud. Secretaría de Salud. Plan Nal de Desarrollo 2001-2006.

5. Sesman A, Barceló-de la Isla R., Herrera-Rosas A. Espejo-Plasencia J. Avila-Figueroa L. Velasquillo-Martínez M. Estudio comparativo de hueso craneal generado en un modelo experimental de osteogénesis en conejos. Acta Pediatr Mex 2010;31(5):206-216.

6. Zheng Y, Ringe J, Liang Z, Loch A, Chen L, Sittinger M. Osteogenic potential of human periosteum-derived progenitor cells in PLGA scaffold using allogeneic serum. J Zhejiang Univ Science B 2006;7(10):817-824.

7. Chang H, Knothe-Tate ML. The Periosteum: Tapping into a Reservoir of Clinically Useful Progenitor Cells. Stem Cells Transl Med 2012;1:480-491.

8. Roberts SJ, van Gastel N, Carmeliet G, Luyten FP. Uncovering the periosteum for skeletal regeneration: The stem cell that lies beneath. Bone 2014;70C:10-18. doi: 10.1016/j.bone.2014.08.007. Epub 2014 Sep 2, 2015.

9. Lin Z, Fateh A, Salem DM, Intini G. Periosteum: biology and applications in craniofacial bone regeneration. J Dent Res 2013;93(2):109-16. doi: 10.1177/0022034513506445. Epub 2013 Oct 2, 2014.

10. Zhang X, Awad H, O'Keefe RJ, Guldberg RE, Schwarz EM. A Perspective Engineering Periosteum for Structural Bone Graft Healing. Clin Orthop Relat Res 2008;466:1777-1787.

11. Syed-Picard FN, Shah GA, Costello BJ, Sfeir C. Regeneration of periosteum by human bone marrow stromal cell sheets. J Oral Maxillofac Surg. 2014;72(6):1078-83. doi: 10.1016/j.joms.2014.02.005. Epub 2014 Feb 11, 2014.

12. Kneser U., Schaefer D.J., Munder B., Klemt C., Andree C.and Stark G.B: Tissue engineering of bone. Min Invas Ther \& Allied Technol 2002;11(3) 107-116. 
13. Sesman-Bernal AL, León-Pérez JA, Fernández-Sobrino G. Actualidades en regeneración y remodelación ósea craneal. Revisión de la literatura. Acta Pediatr Mex 2007;28(5):183-92.

14. Losee J, Karmacharya J, Gannon F, Slemp A, Ong G, Hunenko O, Gorden A, Bartlett S, Kirschner R: Reconstruction of the Immature Craniofacial Skeleton with a Carbonated Calcium Phosphate Bone Cement. Interaction with Bioresorbable Mesh. The Journal of Craniofacial Surgery 2003;14(1):117-124.

15. Sesman A, Ruvalcaba E, Herrera A, Sánchez GS, Lecona H, Baena-Ocampo L, Solis L, Ávila H, García De La Puente S, Vargas B, Guerrero X, Velasquillo C. Morphological Study Of Bone Cranial In Athymic Mice. Int J Morphol 2013; 31(1):321-328.

16. Chim H, Gosain AK. Biomaterials in Craniofacial Surgery Experimental Studies and Clinical Application. J Craniofac Surg 2009;20(1): 29-33.

17. Eppley Barry L. Experimental Assessment of the revascularization of Acellular Human Dermis for Soft-Tissue Augmentation. Plast Reconstr Surg 2001;107(3):757-762.

18. Schantz JT, Hutmacher DW, Chim H, Ng KW, Lim TC, Teoh SH. Induction of ectopic bone formation by using human periosteal cells in combination with a novel scaffold technology. Cell Transplant 2002;11(2):125-3.

19. Hutmacher DW, Sittinger M. Periosteal cells in bone tissue engineering. Tissue Eng 2003;9 Suppl 1:S45-64.

20. Breitbart AS, Grande DA, Kessler R, Ryaby JT, Fitzsimmons RJ, Grant RT. Tissue engineered bone repair of calvarial defects using cultured periosteal cells. Plast Reconstr Surg 1998;101:567-574.

21. Pittenger MF1, Mackay AM, Beck SC, Jaiswal RK, Douglas R, Mosca JD, Moorman MA, Simonetti DW, Craig S, Marshak DR. Multilineage potential of adult human mesenchymal stem cells. Science 1999;284(5411):143-7.

22. Dominici M1, Le Blanc K, Mueller I, Slaper-Cortenbach I, Marini F, Krause D, Deans R, Keating A, Prockop Dj, Horwitz E. Minimal criteria for defining multipotent mesenchymal stromal cells. The International Society for Cellular Therapy position statement. Cytotherapy 2006;8(4):315-7.

23. Ferretti C, Mattioli-Belmonte M. Periosteum derived stem cells for regenerative medicine proposals. Boosting current knowledge. World J Stem Cells 2014; 6(3):266-77. doi: 10.4252/wjsc.v6.i3.266, 2014.

24. Fakhry M, Hamade E, Badran B, Buchet R, Magne D: Molecular mechanisms of mesenchymal stem cell differentiation towards osteoblasts. World J Stem Cells 2013;5(4): 136-148. 
25. Zhang Zhiyuan: Bone regeneration by stem cell and tissue engineering in oral and maxillofacial region. Front. Med 2011;5(4): 401-413. 
Table Legends

Table 1. The Primers sequences and temperature used for RT-PCR. 


\section{Figures Legends}

Figure 1. Cell Viability and Osteogenic Phenotype (A) Cell Viability assessed by Live/Dead assay showing homogeneous distribution of live cells on the Osteogenic Unit (OU) (B) Gene expression of Runx-2, OPN and Col-I after 2-4 weeks in all seven samples. (C-G). Flow Cytometry Analysis of periosteal cells expressing: (C) 92.87\% of CD90, (D) $48.91 \%$ of CD73, (E) $2.38 \%$ of CD166 and for hematopoietic markers (F) $2.15 \%$ of CD34, (G) $0.82 \%$ of CD45 y (H) $0.27 \%$ of CD14. 


\section{Figures Legends}

Figure 2. Cells harvested from the biopsy and seeded into the $\mathrm{OU}$ retain their phenotype and promote bone formation. H\&E Staining of de novo tissue (a). This shows the tissue from the experimental group implanted with an OU graft of $5 \mathrm{~mm}^{2}$ in the skull, after three months. New bone tissue was observed, including bone trabeculae, osteoprogenitor cells and osteoblasts. The control group only showed connective tissue on the borders of the bone defects (b). Immunohistochemistry from the de novo tissue. (b-e). Bone markers were positive for (b) $O P N$, (c) Col-I, (d) Runx-2 and (e) FA, arrows in $b$ and $d$ highlight regions with positive markers. Von Kossa staining of the de novo tissue (f). Bone mineralisation is confirmed in the experimental group. 